\title{
Effect of bulk and thin film dielectric overlay on the characteristics of microstrip rejection filter and simple microstriplines
}

\author{
K VIJAYA, M L JADHAV, S A GANGAL and R N KAREKAR \\ Department of Physics, University of Poona, Pune 411007 , India
}

\begin{abstract}
The changes in the characteristics of microstrip rejection filter and simple microstriplines due to bulk and thin film dielectric overlay are reported in this paper. $\mathrm{Al}_{2} \mathrm{O}_{3}$ overlay both bulk and thin film increases the $Q$ of the filter. All other overlays decrease the $Q$. $\mathrm{TiO}_{2}$ thin film shows improvement in $Q$ whereas with bulk $\mathrm{TiO}_{2}$ the filtering property is not observed. The effect of overlays on simple lines is to reduce the transmission without much effect in the reflection.
\end{abstract}

Keywords. Microstrip rejection filter; simple microstriplines; dielectric overlay; thin films

\section{Introduction}

The structure of the microstripline may lend itself to the study of microwave properties of materials in the thin film form by using overlay/underlay techniques which result in a change in the effective dielectric constant (Farrar and Adams 1974; Pande and Karekar 1976; Pande 1976).

For a given dielectric substrate the characteristic impedance $\left(Z_{0}\right)$ of the microstripline is governed by the $w / h$ ratio where $w$ is the width of the line on top of the substrate and $h$ is the dielectric thickness (Wheeler 1965). The impedance of the measuring system is normally $50 \Omega$. Thus for maximum power transfer the value of $Z_{0}$ should also be $50 \Omega$. For alumina substrate with $\varepsilon=9 \cdot 6, Z_{0}$ is $50 \Omega$ for $w / h$ ratio of about 1 (Gupta and Singh 1974).

Open microstrip resonators are often employed in MIC techniques as absorption filters. One form is the standard half-wave resonator, open at both sides and coupled over a quarter wavelength with the main transmission line (figure 2). In the design of coupled microstrip structures the odd-mode impedance value is often used (Mullard Tech. Comm. 1972) for arriving at the coupling and the corresponding geometry. Unfortunately a considerable portion of the odd mode field exists in the air (Weirather 1974) which leads to fringing fields and radiative losses, particularly in open circuit resonators. The overlay technique, using $\mathrm{Bi}_{2} \mathrm{O}_{3}$ overlay on $\mathrm{Au}$ microstrip circuits (Pande 1976), is reported to be one of the solutions to this problem.

The aim of the present work is to fabricate copper microstriplines and rejection filter and study their transmission and reflection properties with and without overlay of various dielectric materials. From these observations the properties viz the characteristic impedance, $Q$, rejection, etc are calculated. 


\section{Experimental}

The microstrip lines were obtained using chromium/copper on standard $1^{\prime \prime} \times 1^{\prime \prime}$ $\times 0.025 " 99.66 \%$ pure alumina substrates. Initially a thin film of chromium (thickness $\sim 300 \AA$ ) was vacuum-evaporated at about $2 \times 10^{-5}$ torr onto heated alumina substrates, the substrate temperature being optimized to $100^{\circ} \mathrm{C}$ for best adhesion.

After cooling the substrates to room temperature copper was deposited onto the $\mathrm{Cr}$ to a thickness of approximately $3000 \AA$ in the same cycle. After repeating the process on the other side of the alumina substrate, the thickness of $\mathrm{Cu}$ was increased to about $5 \mu$ by electroplating in a $\mathrm{CuSO}_{4}-\mathrm{H}_{2} \mathrm{SO}_{4}$ bath using the arrangement shown in figure 1. The bath required about 2 litres of plating solution $\left(\mathrm{CuSO}_{4}-200 \mathrm{~g} / 1, \mathrm{H}_{2} \mathrm{SO}_{4}-56 \mathrm{~g} / \mathrm{l}\right.$, potash alum $12 \mathrm{~g} / \mathrm{l}$ ).

The size of the anode was twice that of the cathode so as to obtain a uniform field around the cathode. The $\mathrm{pH}$ of the solution was approximately 2 . This electroplating system was optimized to obtain a uniform pinhole free deposit which did not oxidize easily. For a fixed separation between the electrodes $(7.5 \mathrm{~cm})$ and for a fixed voltage (10 V) a current of $80 \mathrm{~mA}$ gave the best films. When run for $30 \mathrm{~min}$, a thickness of $5 \mu$ was obtained.

The rejection filters and microstriplines were photolithographically delineated on one side of these metallized substrate. The geometry was arrived at by using the standard tables and curves reported by Wheeler (1965) and Bryant and Weiss (1978). We designed a $\lambda / 2$ open circuit resonant, single section maximally flat rejection filter (see figure 2) without overlay, at $f=9.57 \mathrm{GHz}, \lambda_{g}=1.271$ with bandwidth of $2 \%$. In addition stripline masks of different widths were used to study the effect of width on $Z_{0}$ and to optimize the mask width.

For circuit evaluation, the microstrip circuits were mounted in resilient contact MIC test fixture. The performance of the filter and microstripline was evaluated using a network analyser (Hewlett-Packard 8410B). On this system the amplitude as well as the phase of the reflection and transmission coefficients can be measured. Using Smith chart overlay fixed on the polar display, direct evaluation of the input impedance $\left(Z_{\text {in }}\right)$ is

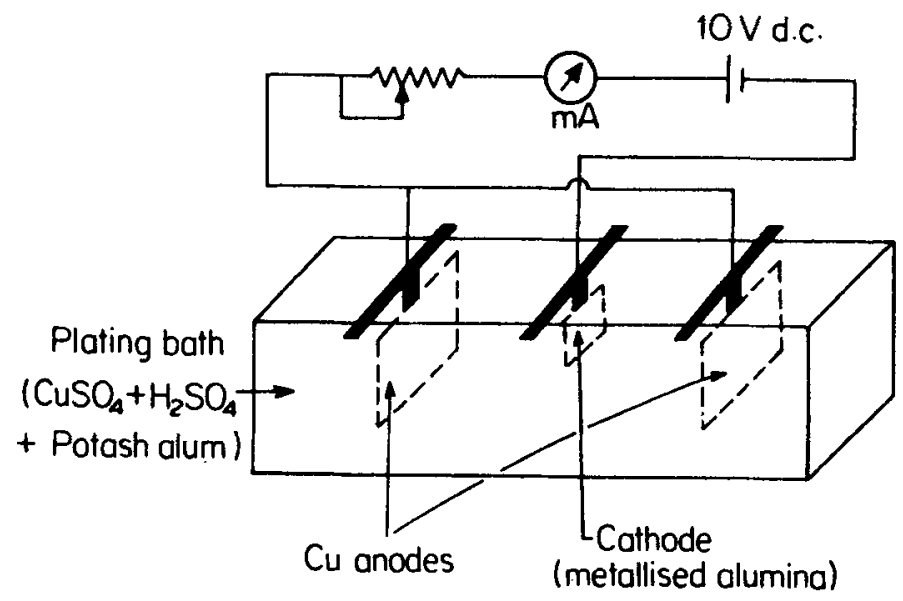

Figure 1. Arrangement for copper electroplating. 


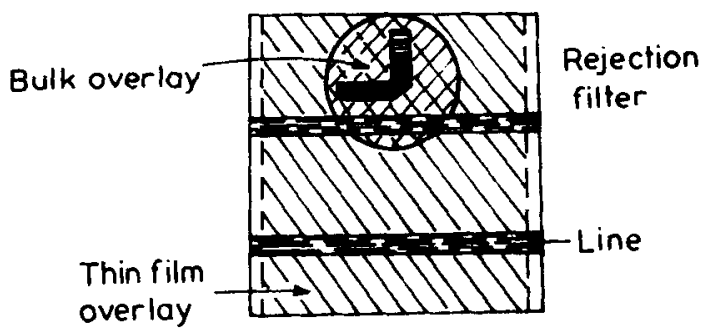

Figure 2. Sketch of the rejection filter and single microstripline with thin film overlay $\left(\lambda_{0}=1.271 \mathrm{~cm}\right)$.

possible. The $Z_{\text {in }}$ data, obtained in the frequency range of 2 to $12 \mathrm{GHz}$, were used to calculate the characteristic impedance $Z_{0}$ of the microstripline, using the equation

$$
Z_{\text {in }}=Z_{0}\left(\frac{Z_{L}+Z_{0} \tan \beta l}{Z_{0}+j Z_{L} \tan \beta l}\right)
$$

where $Z_{L}$ is the load impedance $=50 \Omega, \beta$ is the propagation constant and $l$ is the length of the stripline. Both the bulk and thin film overlays were tried on the filters and microstriplines. The bulk overlays of $\mathrm{Bi}_{2} \mathrm{O}_{3}, \mathrm{TiO}_{2}$ and $\mathrm{ZnS}$ were in pellet form (about $1 \mathrm{~cm}$ in diameter and $2 \mathrm{~mm}$ thick). Those of $\mathrm{Al}_{2} \mathrm{O}_{3}$ and 0211 corning glass were in the form of plates of size $2 \mathrm{~cm} \times 1 \mathrm{~cm}$. The thickness was $0.5 \mathrm{~mm}$ for corning glass and $0.26 \mathrm{~mm}$ for $\mathrm{Al}_{2} \mathrm{O}_{3}$. In any case the dimensions of these bulk overlays were such that they covered the entire coupline area of the filter.

For the film overlays, $\mathrm{Al}_{2} \mathrm{O}_{3}, \mathrm{Bi}_{2} \mathrm{O}_{3}, \mathrm{TiO}_{2}$ and $\mathrm{ZnS}$ and PAN were tried. $\mathrm{Al}_{2} \mathrm{O}_{3}$ was deposited by chemical vapour deposition. The substrates were heated in a nitrogen atmosphere to $375^{\circ} \mathrm{C}$ and a mixture of aluminium isopropoxide $\left(\mathrm{Al}\left(\mathrm{OC}_{3} \mathrm{H}_{7}\right)_{3}\right)$ vapours and $\mathrm{N}_{2}$ gas was passed over them. Due to the pyrolysis of $\mathrm{Al}\left(\mathrm{OC}_{3} \mathrm{H}_{7}\right)_{3}$ at $375^{\circ} \mathrm{C}, \mathrm{Al}_{2} \mathrm{O}_{3}$ is deposited on the substrate. $\mathrm{Bi}_{2} \mathrm{O}_{3}$ films were obtained by vacuum evaporation of bismuth and subsequent oxidation in atmospheric air at a temperature of $165^{\circ} \mathrm{C}$ for about $90 \mathrm{~min}$, and also by reactive ion plating. These overlays of $\mathrm{Al}_{2} \mathrm{O}_{3}$ and $\mathrm{Bi}_{2} \mathrm{O}_{3}$ have some problem of oxidation and peeling because of the heat treatment required. $\mathrm{TiO}_{2}$ and $\mathrm{ZnS}$ were obtained by vacuum evaporation without much difficulty. PAN (polyacrylo-nitrate) films were obtained by plasma polymerization. In all the cases the area covered by overlay was such that it covered the whole substrate except for the contact areas as shown in figure 2.

\section{Results and discussion}

\subsection{Rejection filter}

Figure 3 shows the typical curves of rejection (db) (i.e. transmission) vs frequency for the filter with and without bulk overlay for various overlay materials. Figure 4 shows rejection vs frequency curves for filters with thin film overlay. It is seen from figure 3 that the bulk overlays shift the centre frequency $\left(f_{0}\right)$ to the lower frequency side. Except for $\mathrm{Al}_{2} \mathrm{O}_{3}$ all other overlays have the effect of reducing the $Q . \mathrm{TiO}_{2}$ overlay decreases the transmission at all frequencies from 8-12 GHz and the sample does not show filter 


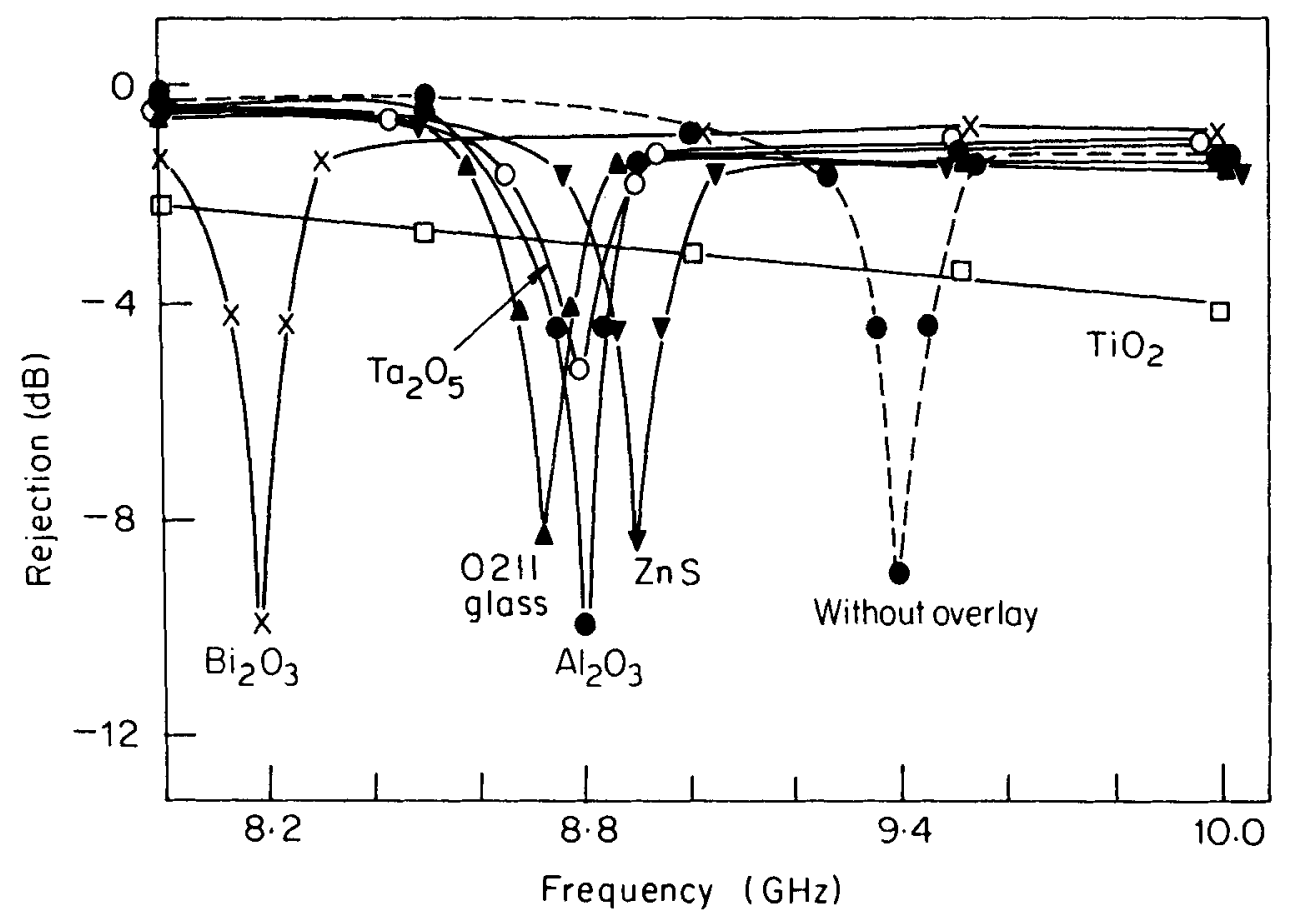

Figure 3. Graph of rejection (db) vs frequency $(\mathrm{GHz})$ for rejection filter with and without bulk overlay.

properties. This shows that the higher thickness of the overlay in some way makes the filter more lossy. This may be due to the presence of some other higher modes, like surface waves. The thickness effect was studied only for $\mathrm{Bi}_{2} \mathrm{O}_{3}$ bulk overlay which shows improvement in $Q$ (even compared to the one without overlay) at a lower thickness of $0.9 \mathrm{~mm}$.

Table la gives the data of $Q$ for filter with and without $\mathrm{Al}_{2} \mathrm{O}_{3}$ and 0211 corning glass bulk overlay. It shows that there is an increase in $Q$ and rejection after $\mathrm{Al}_{2} \mathrm{O}_{3}$ bulk overlay (except in one sample). This shows that the overlay has tightened the coupling and reduced the losses. For 0211 glass there is decrease in $Q$ for all the samples. Table $1 \mathrm{~b}$ gives the data for other bulk overlays.

From figure 4 (for the thin film overlay) it is seen that for $\mathrm{Al}_{2} \mathrm{O}_{3}$ (thickness $\sim 4000 \AA$ deposited by CVD) there is a shift in frequency and also improvement in $Q$ from 84.08 to 112. $\mathrm{Bi}_{2} \mathrm{O}_{3}, \mathrm{TiO}_{2}$ and $\mathrm{Ta}_{2} \mathrm{O}_{5}$ do not show any shift in frequency. $\mathrm{TiO}_{2}$ film of thickness $900 \mathrm{~A}$ also shows improvement in $Q$ from 158.5 to 172.9 . Thin film overlay of $\mathrm{TiO}_{2}$ is better than bulk $\mathrm{TiO}_{2}$ overlay. For $\mathrm{Bi}_{2} \mathrm{O}_{3}$ and $\mathrm{Ta}_{2} \mathrm{O}_{5}$ there is decrease in $Q$, for $\mathrm{Bi}_{2} \mathrm{O}_{3}$ from 189 to 118 and for $\mathrm{Ta}_{2} \mathrm{O}_{5}$ from 188 to $156 \cdot 6$. $\mathrm{ZnS}$ films reacted with copper, spoiling the microstrip structure itself, so the effect of $\mathrm{ZnS}$ thin film overlay could not be studied. Plasma-polymerized PaN overlay gave rise to shift in $f_{0}$ from 9.52 to 9.49 and decrease in $Q$ from 190 to 158.

An attempt was also made to use the frequency shift and $Q$ of filters with overlay to get an idea about the material properties of the overlay. The procedure was as follows. 

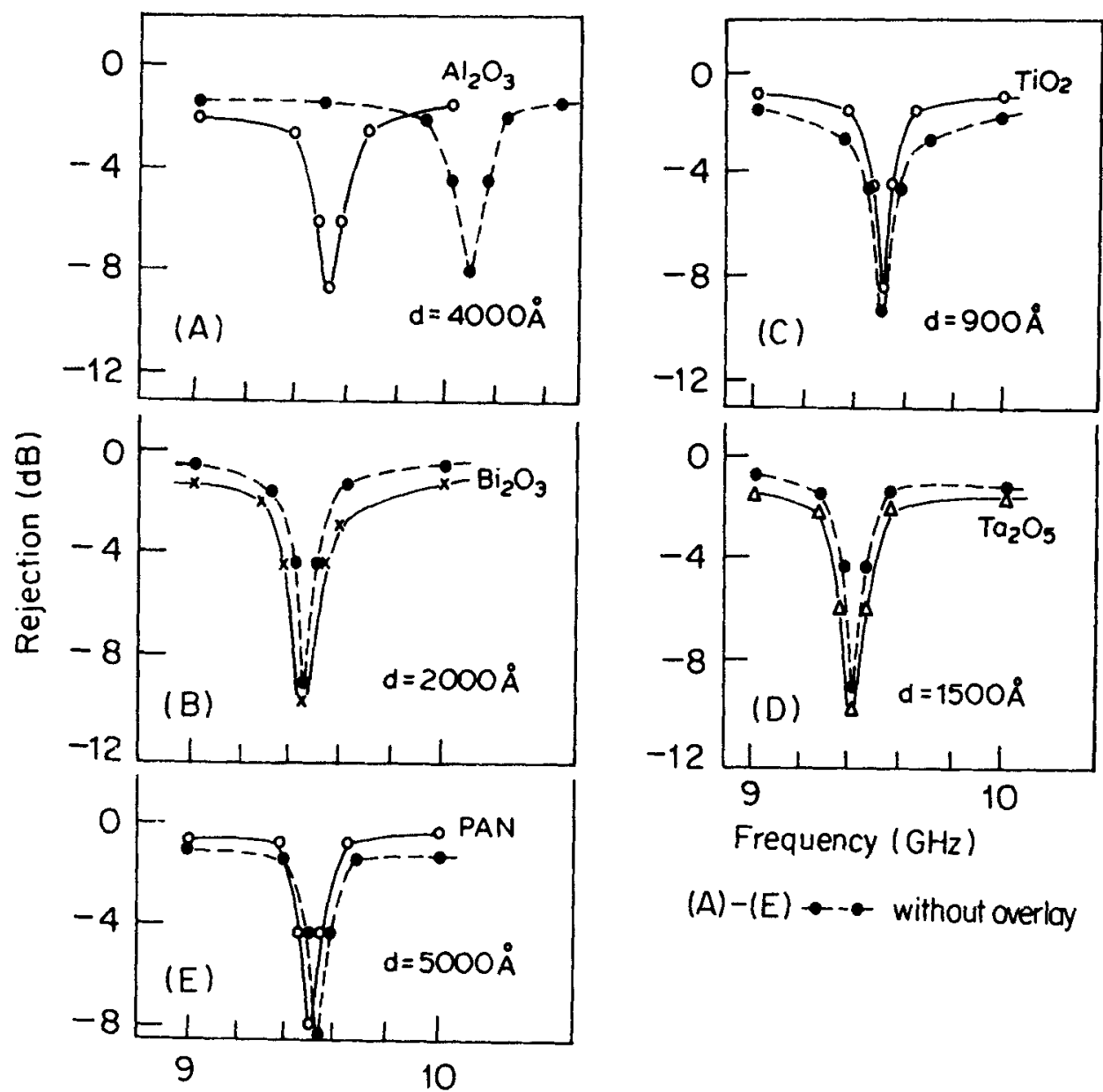

Frequency $(\mathrm{GHz})$

(A) $-(E)-\cdots$ without overlay

Frequency $(\mathrm{GHz})$

Figure 4. Graph of rejection (db) vs frequency $(\mathrm{GHz})$ for rejection filter with and without thin film overlay.

The $\varepsilon_{\text {eff }}$ of the stripline without overlay was calculated using the formula of Owens (1976).

$$
\varepsilon_{\mathrm{eff}}=\frac{\varepsilon_{r}+1}{2}\left\{1+\frac{29 \cdot 98}{Z_{0}}\left(\frac{2}{\varepsilon_{r}+1}\right)^{1 / 2}\left(\frac{\varepsilon_{r}-1}{\varepsilon_{r}+1}\right)\left(\ln \frac{\pi}{2}+\frac{1}{\varepsilon_{r}} \ln \frac{4}{\pi}\right)\right\}^{2}
$$

where $\varepsilon_{r}=9 \cdot 6$, the dielectric constant of the alumina substrate. $Z_{0}$ was assumed to be $50 \Omega$ as an approximation. From this formula $\varepsilon_{\text {eff }}$ without overlay comes out to be 6.077. Using this value of $\varepsilon_{\text {eff }}$ and the experimental resonant frequency $f_{0}$ without overlay, the guide wavelength $\lambda_{g}$ was calculated for each sample using the relation,

$$
\lambda_{g}=\frac{\lambda_{0}}{\sqrt{\varepsilon_{\mathrm{eff}}}}
$$

$\lambda_{0}$ is the free space $\lambda_{0}\left(c / f_{0}\right)$. This is done to account for changes in $\lambda_{g}$ due to delineation. 
Table 1a. Data of $Q$ and rejection of filter with and without bulk $\mathrm{Al}_{2} \mathrm{O}_{3}$ and 0211 glass overlays

\begin{tabular}{|c|c|c|c|c|c|c|c|c|c|}
\hline \multirow[b]{3}{*}{$\begin{array}{c}\text { Sample } \\
\text { No. }\end{array}$} & & & & \multicolumn{6}{|c|}{ Bulk overlay of $\mathrm{Al}_{2} \mathrm{O}_{3}$ and 0211 glass } \\
\hline & \multicolumn{3}{|c|}{ Without overlay } & \multicolumn{3}{|c|}{$\mathrm{Al}_{2} \mathrm{O}_{3}$} & \multicolumn{3}{|c|}{0211 glass } \\
\hline & $\begin{array}{c}f_{0} \\
\mathrm{GHz}\end{array}$ & $Q$ & $\begin{array}{l}\text { Rej } \\
d b\end{array}$ & $\begin{array}{c}f_{0} \\
\mathrm{GHz}\end{array}$ & $Q$ & $\begin{array}{l}\text { Rej } \\
d b\end{array}$ & $\begin{array}{c}f_{0} \\
\mathrm{GHz}\end{array}$ & $Q$ & $\begin{array}{l}\text { Rej } \\
\mathrm{db}\end{array}$ \\
\hline 3 & 9.64 & 160 & 4.9 & 9.05 & 181 & $5 \cdot 4$ & & & \\
\hline 41 & 9.47 & 145.6 & 4.9 & 8.82 & 147 & $5 \cdot 6$ & 8.72 & 96.8 & $4 \cdot 3$ \\
\hline 44 & 9.51 & 158.5 & $6 \cdot 1$ & 8.78 & $175 \cdot 6$ & $6 \cdot 1$ & 8.76 & $109 \cdot 5$ & $4 \cdot 5$ \\
\hline 48 & 9.52 & $190 \cdot 4$ & $5 \cdot 4$ & 8.94 & 149 & $5 \cdot 4$ & 8.67 & $123 \cdot 8$ & 4.8 \\
\hline 53 & $9 \cdot 40$ & $188 \cdot 0$ & $6 \cdot 1$ & 8.80 & $251 \cdot 4$ & 6.9 & 8.72 & $158 \cdot 5$ & $5 \cdot 4$ \\
\hline B & 9.57 & $106 \cdot 3$ & 3.9 & 8.92 & $111 \cdot 5$ & $4 \cdot 5$ & 8.81 & $80 \cdot 10$ & 3.9 \\
\hline $\mathrm{D}$ & 9.65 & 175.4 & 4.9 & 8.88 & 253.8 & $6 \cdot 1$ & 8.87 & $108 \cdot 75$ & 4.9 \\
\hline $\mathbf{H}$ & $9 \cdot 71$ & 107.8 & 3.9 & $9 \cdot 19$ & $13 \cdot 13$ & $4 \cdot 5$ & $9 \cdot 0$ & 90.0 & $4 \cdot 1$ \\
\hline $\mathbf{J}$ & 9.56 & 73.5 & $3 \cdot 0$ & 8.85 & $126 \cdot 4$ & $3 \cdot 9$ & 8.82 & $76 \cdot 7$ & $3 \cdot 0$ \\
\hline $\begin{array}{l}\text { Average } \\
\text { values }\end{array}$ & $\begin{array}{r}\varepsilon_{\mathrm{e}} \\
\tan \delta_{\mathrm{c}} \\
\sigma_{\mathrm{e}}\end{array}$ & 6.077 & ' $\mho-\mathrm{cm}$ & $\begin{array}{r}\varepsilon_{\mathrm{eff}} \\
\tan \delta_{\mathrm{eff}} \\
\sigma_{\mathrm{en}}\end{array}$ & $7 \cdot 169$ & $\begin{array}{l}-3 \\
-\mathrm{C}-\mathrm{cm}\end{array}$ & $\begin{array}{r}\varepsilon \\
\tan \delta \\
\sigma\end{array}$ & $\begin{array}{l}=7.19 \\
=9.19 \times \\
=1.70 \times\end{array}$ & -3 \\
\hline
\end{tabular}

Table 1b. Data of $Q$ and rejoction of filter with other bulk averlays

\begin{tabular}{|c|c|c|c|c|c|c|c|c|c|c|c|c|c|}
\hline \multicolumn{3}{|c|}{ Without overlay } & \multicolumn{11}{|c|}{ Bulk overiays of } \\
\hline & & & \multicolumn{3}{|c|}{$\mathrm{Bi}_{2} \mathrm{O}_{3}$} & \multicolumn{3}{|c|}{$\mathrm{ZnS}$} & \multirow[b]{2}{*}{$\begin{array}{c}f_{0} \\
\mathrm{GHz}\end{array}$} & \multirow[b]{2}{*}{$Q$} & \multirow[b]{2}{*}{$\begin{array}{l}\text { Rej } \\
\mathrm{db}\end{array}$} & \multirow[b]{2}{*}{$\underset{\mathrm{GHz}}{f_{0}} Q$} & \multirow[b]{2}{*}{$\begin{array}{l}\text { Rej } \\
\mathrm{db}\end{array}$} \\
\hline $\begin{array}{c}f_{0} \\
\mathrm{GHz}\end{array}$ & $Q$ & $\begin{array}{l}\text { Rej } \\
d b\end{array}$ & $\begin{array}{c}f_{0} \\
\mathrm{GHz}\end{array}$ & $Q$ & $\begin{array}{l}\text { Rej } \\
d b\end{array}$ & $\begin{array}{c}f_{0} \\
\mathrm{GHz}\end{array}$ & $Q$ & $\begin{array}{l}\text { Rej } \\
\text { db }\end{array}$ & & & & & \\
\hline $9 \cdot 64$ & 160 & 49 & 8.52 & 31.5 & $1 \cdot 4$ & $9 \cdot 12$ & 102 & 3.9 & 8.79 & $46 \cdot 3$ & $2 \cdot 2$ & $\begin{array}{l}\text { No filter } \\
\text { character }\end{array}$ & \\
\hline $9 \cdot 52$ & $190 \cdot 4$ & $5 \cdot 4$ & $9 \cdot 28$ & $42 \cdot 2$ & $3 \cdot 2$ & & & & & & & & \\
\hline $9 \cdot 40$ & 188 & $6 \cdot 1$ & $\begin{array}{l}8.18 \\
\text { (thin }\end{array}$ & $\begin{array}{l}204.5 \\
\text { pellet) }\end{array}$ & 6.9 & & & & & & & $\begin{array}{l}\text { No filter } \\
\text { character }\end{array}$ & \\
\hline
\end{tabular}

As a result of overlay, $\varepsilon_{\mathrm{eff}}$ will change to $\left(\varepsilon_{\mathrm{eff}}\right)$, thus changing the resonant frequency to $\left(f_{0}\right)_{0}$. Hence by knowing experimental $\left(f_{0}\right)_{0}$ and calculated $\left(\lambda_{g}\right)_{0}$ and using equation (3) again one can get $\left(\varepsilon_{\text {eff }}\right)_{0}$. The values of $\left(\varepsilon_{\text {eff }}\right)_{0}$ thus calculated are given in tables $1 \mathrm{a}$ and $1 \mathrm{~b}$.

From the experimental value of $Q$, the effective loss tangent of the overall configuration can be calculated using the relation

$$
\tan \delta=1 / Q \text {. }
$$

Some typical values are given in tables $1 \mathrm{a}$ and $1 \mathrm{~b}$. Assuming the rejection filter to be a parallel resonant circuit the effective conductivity can be estimated to a first 
approximation using the formula for parallel resonant circuits.

$$
\sigma_{\mathrm{eff}} \approx Q / \omega \varepsilon_{\mathrm{eff}}
$$

It is seen that with overlay there is a reduction in the effective $\tan \delta$ as compared to the one without overlay. Only $\tan \delta$ of $\mathrm{Al}_{2} \mathrm{O}_{3}$ is available in literature and is $\sim 6 \times 10^{-4}$. Our values are effective and further analysis is being done to separate the dielectric properties from the effective values.

\subsection{Single microstriplines}

Figure 5 shows the variation of $Z_{0}$ with frequency in the range of 2 to $12 \mathrm{GHz}$ for microstriplines with widths varying from 18 to 28 mils. It is seen that $Z_{0}$ varies in the range of $20 \Omega$ to $95 \Omega$ randomly about the expected value of 50 ohms. Although some sort of oscillatory behaviour is observed, it is difficult to relate this to width variation. In all cases, except for the 18 mils line the scatter is more pronounced at the higher

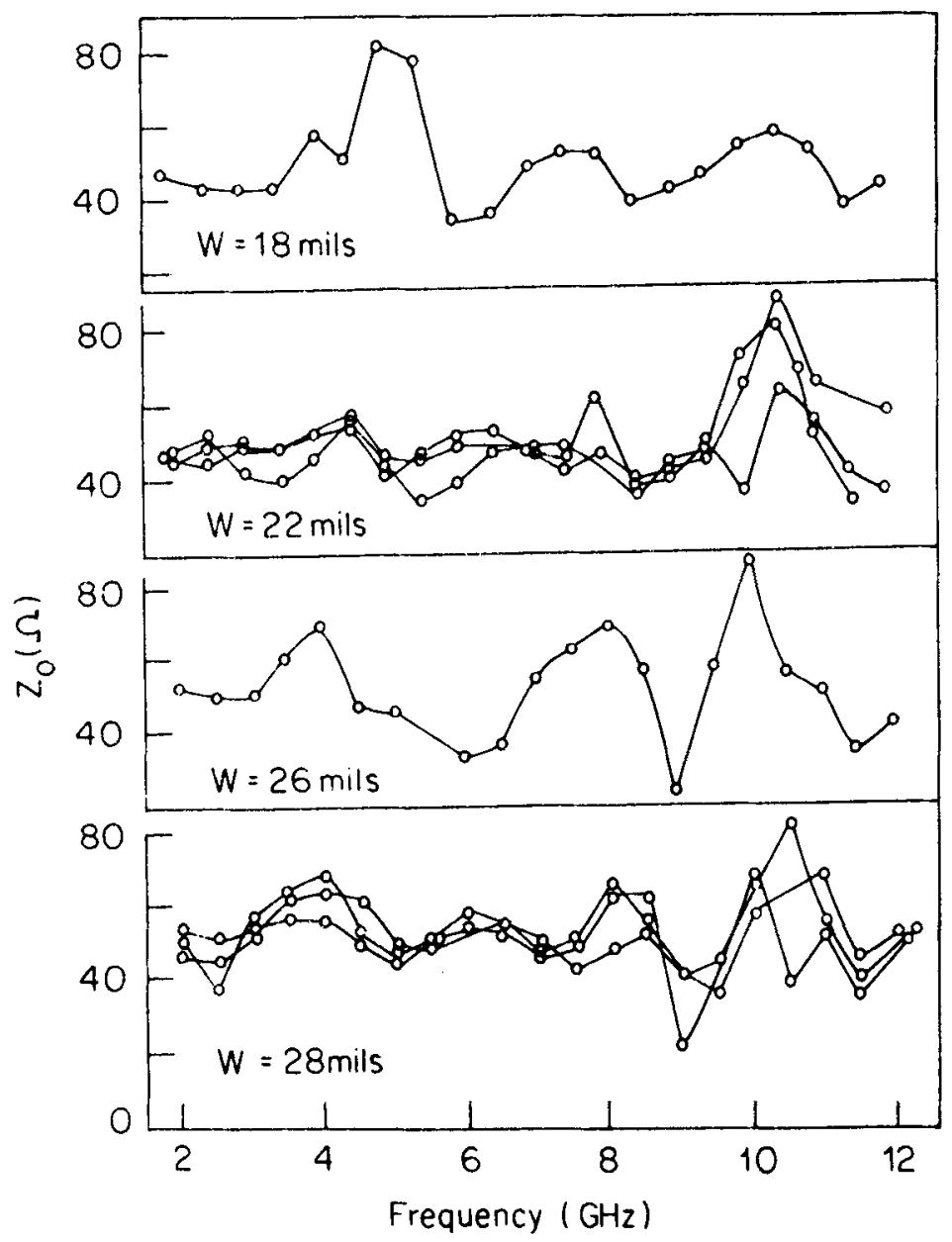

Figure 5. Variation of characteristic impedance $\left(Z_{0}\right)$ with frequency for striplines of different widths. 
frequencies $(8-12 \mathrm{GHz})$. In the microwave range, $Z_{0}$ is expected to show a steady increase with frequency (Krage and Haddad 1972). This is because of the change in the effective dielectric constant with frequency and also changes in the resistivity of conductor material.

The observed random variation of $Z_{0}$ with frequency could be due to the contacts between the microstrip and the ommni spectra (OSM) launchers which are actually coaxial to microstrip connectors used to connect the microstrip to the rest of the measuring system. Bianco et al (1976) characterized the effect of launcher on a system of microstrips and active devices. They too report random oscillatory behaviour of the scattering parameter $S_{11}$ and $S_{22}$. Since the results are heavily affected by launcher discontinuities, there seems to be no justification to discuss the frequency dependance of $Z_{0}$ in any further depth.

3.2a Overlay effects on losses: In order to study the effect of overlay on the losses present in the microstripline the power reflection and transmission coefficients were studied for both bulk and thin film overlays. The typical graphs of $\rho^{2}$ and $T^{2}$ versus frequency for bulk overlay effect are shown in figure 6. In all cases except for $\mathrm{TiO}_{2}$ the reflection reduced as a result of bulk overlay. The transmission is also slightly reduced except in $\mathrm{TiO}_{2}$, where it reduced almost by $50 \%$. However, the values of $\rho^{2}$ and $T^{2}$ are very critically dependant on size and position of the overlays. Since thin film overlays had to be tried on different samples only $\Delta T$ and $\Delta \rho$ were studied as a result of overlay. Only PAN (reactive ion-plated), $\mathrm{Bi}_{2} \mathrm{O}_{3}$ and $\mathrm{TiO}_{2}$ showed increased average transmission as shown in table 2. The reflection coefficient measured at $8 \mathrm{GHz}$ did not show much change (within variability limits). More careful experimentation is needed after considering the effect of discontinuities and variabilities.

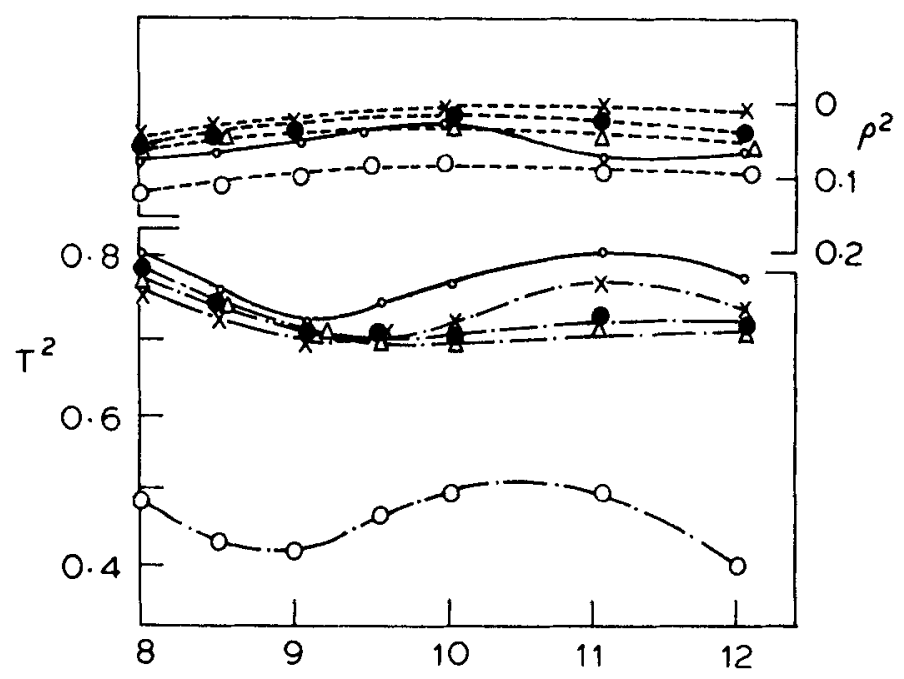

Figure 6. Variation of transmission and reflection coefficients as a function of frequency for single stripline with and without bulk overlay. (O) $\mathrm{Al}_{2} \mathrm{O}_{3} ;(\times) \mathrm{Bi}_{2} \mathrm{O}_{3} ;(\Delta) 0211$ glass; (O) $\mathrm{TiO}_{2}$. 
Table 2. Effect of thin film overlay on microstripline, $\rho^{2}$ and $T^{2}$

\begin{tabular}{lcc}
\hline Material & $\begin{array}{c}\Delta T^{2} \\
\text { (average) }\end{array}$ & $\Delta \rho^{2}(8 \mathrm{GHz})$ \\
\hline $\mathrm{PAN}$ & +0.09 & -0.04 \\
$\mathrm{TiO}_{2}$ & +0.13 & 0 \\
$\mathrm{ZnS}_{\mathrm{Bi}_{2} \mathrm{O}_{3} \text { (oxidized) }}$ & -0.67 & - \\
$\mathrm{Bi}_{2} \mathrm{O}_{3}$ (reactive ion-plated) & -0.05 & 0 \\
$\mathrm{Al}_{2} \mathrm{O}_{3}$ (cVD) & +0.13 & -0.004 \\
\hline
\end{tabular}

\section{Acknowledgements}

The authors gratefully acknowledge the permission given by Mr R P Arora of IAT, Pune for the extensive use of network analyser. Thanks are also due to $\mathrm{Mr} \mathrm{D}$ Chenna for helping in cvD of $\mathrm{Al}_{2} \mathrm{O}_{3}$. The authors also acknowledge the financial assistance from the Department of Science and Technology, New Delhi.

\section{References}

Bianco B et al 1976 IEEE Trans. Instrum. Meas. IM-25 320

Bryant T G and Weiss J A 1978 IEEE Trans. Microwave Theory Tech. MTT-16 1021 Farrar A and Adams A T 1974 IEEE Trans. Microwave Theory Tech. MTT-22 889

Gupta K C and Singh A 1974 Microwave integrated circuits (New York: Wiley, Eastern) p. 13

Krage M K and Haddad G I 1972 IEEE Trans. Microwave Theory Tech. MTT-20 678

Mullard Tech. Commun. No. 1161972 p. $117-187$

Owens R P 1976 Radio Electron. Eng. 46360

Pande M K and Karekar R N 1976 IEEE Trans. Microwave Theory Tech. MTT-24 262

Pande M K 1976 Ph.D. Thesis, Poona University, Pune

Weirather R R 1974 IEEE Trans. Microwave Theory (Lett.) MTT-22 70

Wheeler A 1965 IEEE Trans. Microwave Theory Tech. MTT-13 172 